\title{
Sensory characteristics of carbon fiber based strain sensors and integration techniques into textile reinforced structures for in situ monitoring of thermoplastic composites
}

\author{
E. Haentzsche, A. Nocke, A. Matthes, Ch. Cherif \\ Institute of Textile Machinery and High Performance Material Technology, Dresden University of Technology, \\ George-Baehr-Str. 3c, 01069 Dresden, Germany
}

Corresponding author: eric.haentzsche@tu-dresden.de

\begin{abstract}
:
In this study, the sensory characteristics of quasi-one-dimensional carbon filament yarn (CFY) based strain sensor manufactured by the usage of different textile-technological manufacturing processes for one-step integration in textile reinforcement structures and the sensor usability for non-destructive in-situ structural health monitoring of local and/or global mechanical loading conditions in endless fiber reinforced thermoplastics (FRTP) is reported.
\end{abstract}

Key words: in situ structural health monitoring, fiber reinforced thermoplastics (FRTP), carbon filament based strain sensor, textile-technological manufacturing processes, electro-mechanical characteristics

\section{Introduction}

Lightweight structures based on fiber-reinforced composites offer many advantages in the design of material- and energy-efficient components in comparison to conventional structures. There is an increasing implementation of such structures, especially in mobile application areas (e.g. aerospace, marine, alternative power generation, sports or the leisure sector) for this reason. At this time, lightweight structures typically rely on thermoset resins, but the advantages of thermoplastic composites, like high fracture toughness against impact damages, ductility, easy recycling, short processing time, various shaping possibilities, weldability, low cost and resistance to media and corrosion attract a growing interest from both the academic community and industry $[1,2,3,4]$.

As for conventional components, the metrological capture of the structural behavior is crucial for the constructive designing and the structural monitoring of FRTP components. The mechanical behavior of thermoplastic composites under loading in service has not been sufficiently investigated. Hence structural health monitoring is required to prevent fatal damage during usage $[5,6,7,8]$.
However, the integration of functional components as strain sensors into such materials is still a challenge. Above all, the built-in sensors should not affect the mechanical properties of textile reinforced composites.

In the midst of numerous types of conventional sensors, electrically conducting CFY $[9,10]$ offer a simple, cost-effective, and durable option for continuous and non-destructive in situ monitoring of local and/or global mechanical loading conditions as well as crack initiation and crack propagation processes in difficult or inaccessible areas within spitting distance of the structural load-bearing layers of fiber-reinforced composites. In addition, the use of such yarns provides the possibility of a processcompatible integration during production of the reinforcement fabric. The electro-mechanical behavior of CFY can be used analogously to the conventional strain gauge technique. If the adhesion of these CFY-based strain sensors (CFYS) to the surrounding FRTP is sufficient enough, a change in geometry and thereby in electric resistivity of the CFY is caused by any mechanical load or damage of the sensor carrying FRTP component $[10,11,12$, 13]. 
The physical coupling of such textile-based sensor elements with the reinforcement structure, which can be influenced by different interlacing techniques, as well as adhesion forces acting between the CFY and the polymer matrix of the FRTP generated by appropriated coupling agents and/or physical or rather chemical functionalization of the filaments themselves, is a decisive factor for the sensor properties (e.g. sensitivity or $k$-factor, linearity and hysteresis). Particularly with regard to the influences of interlacing technique (crimp) and undulation of the CFY in the reinforcement fabric plane and their respective resulting friction forces on the sensory characteristics realized by weaving have not been investigated so far. On these grounds, they are subject of the following study.

\section{Sensor materials and technological integration in textile reinforcement structures}

For the CFY, rovings of the type Toray Torayca ${ }^{\circledR}$ T300B-1000-50B and Toho Tenax ${ }^{\circledR}-\mathrm{J}$ HTA40-F15 (cf. Tab. 1) are used as strain sensor. The sensory properties of the bare roving's, i.e. they are not embedded into a plastic matrix, are determined directly under different mechanical load scenarios, as well as integrated in FRTP composite structures. However, only rovings with 1,000 filaments are used for the baseline investigations for reasons of sensitivity of CFYS under mechanical exposures, enhancement of the fiber infiltration by the thermoplastic matrix and processability.

CFYS are integrated into woven structures of commingled glass-fiber polypropylene (GF/PP) hybrid yarn. These hybrid yarn in a volume combination of $52 \%$ and $48 \%$ respectively, is used for the woven reinforcement structure in warp and weft direction (cf. Tab. 1) and manufactured at ITM by commingling technique $[14,15]$. For all structures, a quasi-one-dimensional direction of the sensor thread is realized to achieve a better comparability between the manufactured specimens.

Weaving is predestinated for the integration of textile-based sensor elements and networks because of its versatile possibilities for real structural embedding, i.e. crimp, of the CFY in the textile reinforcement for further FRTP composites. For evaluating the influence of the structural embedding on the sensory characteristics of CFYS, a gradual increase of the friction forces between the textile reinforcement structure and the used CFY has been achieved by the variation of the interlacing depth (Fig. 1) by weaving in the warp direction of a multilayer weave (MLW) with three plies of warp on a Van de Wiele VTR 23 double-rapier loom equipped with a jacquard machine.

\section{Electrical contacting and preparation of test specimens}

For implementation of the CFYS in conventional electric measurement arrangements, like the Wheatstone bridge, a conductive interconnection is essential. For that purpose, a variety of possibilities for CFY before and after consolidating the base FRTP structure are described, e.g. clips [10], silver conductive paints, conductive adhesives, metal splices, wrapping with wire [12] and electroplated coating [13], but a universal economical solution for CFYS connectors in composite has not yet to be found. Soldered copper foil contacts fitted on the CFYS before consolidating of the FRTP [11] are used finally, because of their non-elaborate making and the very low transfer resistivity in a range of $R_{\text {transfer }}=(20 \ldots 92) \mathrm{m} \Omega$.

After contacting, the woven structures including the CFYS have to be consolidated into thermoplastic composites, wherefore one ply of MLW (laminate orientation code $\left[90^{\circ}, 0^{\circ}, 90^{\circ}, 0^{\circ}, 0^{\circ} \mathrm{CF}\right.$ DMS, $\left.90^{\circ}, 0^{\circ}, 90^{\circ}\right]$ ) is pressed in a laboratory platen press machine P $300 \mathrm{PV}$ to obtain composite plates of $274 \times 274 \times 1.0 \mathrm{~mm}^{3}$. In this case, the pressing parameters are the same as given in [11], i.e. a temperature of $220^{\circ} \mathrm{C}$ and a pressure of $4.0 \mathrm{MPa}$ over a total holding time of $58 \mathrm{~min}$. According to DIN EN ISO 527-4:1997-07, test specimens of $274 \times 15 \times 1.0 \mathrm{~mm}^{3}$ and a free clamping length of $l_{E}=160 \mathrm{~mm}$ between their affixed tensile force transmission elements are then prepared for various mechanical stress scenarios, such as cyclic tensile load tests, tensile stress tests until structural failure of the FRTP and tensile creep tests directly compared to the behavior of an conventional strain gauge.

\section{Measurement arrangement for the characterization of CFYS}

The change of resistivity in consolidated textile reinforced composites is measured using the WHEATSTONE bridge principle with temperature drift compensation by another unstressed CFYS in the neighbored bridge section (full bridge) and amplified by HBM MGCplus amp, while the tensile loading is applied on an uniaxial tensile testing machine Zwick/Roell Z100 using different specimen holders (type 8487 and 8720 respectively) for bare and integrated CFYS. All tests are performed at standard atmospheric conditions according to DIN EN ISO 139:2011-10. In order to establish a variety of electro-mechanical characteristics, the test specimens are exposed to cyclical tensile load scenarios at first, divided into two phases. During the first phase, the sensor parameters strain sensitivity or $k$-factor (Eq. 1 ) and non-linearity $A_{\text {Lin }}$ (Eq. 2) are determined. In the following phase, flight-of-stairs cycles are integrated for hysteresis 
measurement $A_{H y s_{-} C F Y S}$ (Eq. 3). Tab. 2 depicts the testing parameters.

$$
\begin{aligned}
& =\Delta / \\
& =\frac{\left|\frac{\Delta}{\left(\frac{\Delta}{}\right)} \cdot\right|}{100 \%} \\
& =\frac{\left.\max \mid \frac{\Delta}{(\uparrow)}-\frac{\Delta}{(}{ }_{\downarrow}\right) \mid}{\max \left(\frac{\Delta}{}\right)} \cdot 100 \% \\
& =\frac{\left|()-\left({ }_{0}\right)\right|}{(0)} \cdot 100 \%
\end{aligned}
$$

$R$...resistivity in $\Omega \quad \varepsilon$...elongation in $\mu \mathrm{m} / \mathrm{m}$ or $\%$

During tensile creep tests, according to DIN EN ISO 899-1:2003, the sensor carrying specimen is stressed with constant tensile loads up to $\sigma=(122 \pm 0.1) \mathrm{MPa}$ over a time span of $7.5 \mathrm{~h}$. Thereby, the absolute and relative creep of the FRTP $A_{\text {Creep }}$ (Eq. 4) measured by non-undulated CFYS and conventional strain gauge HBM 1-LY68-3/120A are compared with the effective creep detected by the tensile testing machine's reference elongation measurement system.

\section{Results and Discussion}

Tab. 3 depicts the determined specific values of bare and un-laminated CFY acting as strain sensors. Although same substantial educts and comparable physical characteristics, like tensile strength, breaking elongation and yarn count (cf. Tab. 1), the $k$-factor and thereby linearity of the Torayca ${ }^{\circledR}$ based CFYS are smaller than the specific values of the Tenax ${ }^{\circledR}$ CFYS. Marginal changes of the mechanical properties and irreversible damages of the CFY respectively, caused by wrong storing or physical impacts, e.g. ultraviolet radiation, air humidity or compressive forces, are suspected for that behavior.

Particularly with regard to the strongly distinct viscoelastic material behavior of the surrounding thermoplastic PP matrix, the usually imperfect fibermatrix-interface as well as the adhesion of the CFY in dependance of its crimp with the reinforcement structure, a significant downgrading of sensor's accuracy can be observed by means of the determined specific values of embedded CFYS in FRTP (cf. Tab. 4)

Tab. 4 depicts the reachable specific values of woven CFYS integrated in an FRTP in dependance of the degree of undulation, related to the undulation (crimp) in test series B0.1, whose CFYS are nearly wholly stretched in warp direction, rendering their undulation negligible to non-existent. Fig. 2 shows the developing of the measured signal by the B 0.1
CFYS series. The extent of the displacement caused by the topology of the MLW during the FRTP's consolidation process and accumulated along the integrated length, is assumed to be negligibly small. The characteristic sensor values are valid until a FRTP elongation of $4,000 \mu \mathrm{m} / \mathrm{m}$ or $0.4 \%$ at nominal tensile stresses of $\sigma_{\text {tensile }}=(67.3 \pm 8) \mathrm{MPa}$. It is apparent, that with increasing undulation, i.e. the displacement and deviation of the sensor thread from the direction of major loading caused by the crossing of warp and weft yarn sheets, the $k$-factor and linearity is decreased simultaneously. It is supposed, that a rising degree of undulation and crimp respectively, combined with the traction of a warp thread integrated into the weave in such a way, generates a pseudo-form closure entailing a strong physical link between CFYS and the MLW, which makes the relatively low hysteresis $A_{H y S_{-} C F Y S}$ of the B0.4 sensor types appear plausible. Furthermore, during the flight-of-stairs loading cycles' middle retention levels' strain controlled dwells, strain hysteresis (cf. Fig. 2 and Tab 4, $A_{\text {Hy_ FRTP }}$ ) caused by adjustment delay of the tensile testing machine and/or by relaxation of the FRTP can be observed.

Under continuously increasing tensile load until full structural damage of the sensor-carrying FRTP structure at elongation levels of $\varepsilon=(22,000 \pm 8,800) \mu \mathrm{m} / \mathrm{m} \quad$ or $\quad(2.2 \pm 0.9) \%$ respectively and nominal tensile stresses of $\sigma_{\text {tensile }}=(230 \pm 27) \mathrm{MPa}$, four specific jump discontinuities relating to the sensor's resistivity $\Delta(\Delta R / R)=(2.8 \pm 0.9) \mathrm{m} \Omega / \Omega$ can be monitored by the CYFS series integrated without undulation caused by filament breakages. These saltus can be indicators for the formation of local micro-cracks of the matrix accumulated along the integration length nearby the CFYS. Otherwise, as Fig. 3 depicts, there can be determined no significant global crack initiation and propagation processes in the FRTP structure respectively, in evidence at the $\sigma=\mathrm{f}(\varepsilon)$ developing. The dissimilar slopes for both of the curves follow from a different YOUNG modulus, which is much higher for the CFY in comparison to the FRTP. The increasing slopes after each saltus can be indicators for an improved parallelization and orientation of the CF respectively in direction of the major tensile loading. However, it can be supposed, that the integrated CFYS has no significant or only an evanescently small influence on the mechanical behavior of the sensor carrying FRTP structure with regard to the observed stress-strain developing.

During the tensile creep tests, an indicated absolute creep of the FRTP specimen of $\Delta \varepsilon_{\text {creep_CFYS }}=733 \mu \mathrm{m} / \mathrm{m}$ can be measured in situ by the CFYS series $(R=108.5 \pm 1.1 \Omega)$ without undulation in direction of major loading. For comparison, the conventional metal foil strain 
gauge, HBM 1-LY68-3/120A $\quad(R=120 \pm 0.4 \Omega)$, which is appliqued at the surface of the specimen centered in the geometric middle of its clamping length of $l_{E}=160 \mathrm{~mm}$, shows only a creep of $\Delta \varepsilon_{\text {creep_LY68-3/120A }}=112 \mu \mathrm{m} / \mathrm{m}$. The effective absolute creep of the sensor carrying FRTP structure can be determined to $\Delta \varepsilon_{\text {creep FRTP }}=649 \mu \mathrm{m} / \mathrm{m}$ by the optical elongation pick up sensor Zwick/Roell videoXtens ${ }^{\circledR}$. In a subsequent experimental run, another five specimens out of the same CFYS series are investigated. Here, an indicated absolute $\Delta \varepsilon_{\text {creep_CFYS }}=(1859 \pm 142) \mu \mathrm{m} / \mathrm{m}$ and relative creep of $A_{\text {creep } C F Y S}=(19.2 \pm 1.4) \%$ respectively is mapped via CFYS to the effective FRTP's creep to the amount of $\Delta \varepsilon_{\text {creep FRTP }}=(1457 \pm 223) \mu \mathrm{m} / \mathrm{m}$ or $A_{\text {creep FRTP }}=(15 \pm 2.1) \%$. The creep curves in Fig. 4 depict impressively the significant differently characteristics of both sensor types over the exposure duration. For reasons of the ten-times smaller covered measuring area in comparison to the CFYS, and the conventional strain gauge's adhesive bonded joint with the specimen surface, it indicates a smaller effective creep of the FRTP due to the inhomogeneous elongation field within the clamping length $l_{E}$ of the specimens or due to the anisotropism of such materials in general. Since creep processes appear inhomogeneous over $l_{E}$, it seems plausible therefore, that the effective percentage of the averaged creep stress below the respective sensors in dependance to the dimensions of their active measuring areas are deviated around the observed moduli. As physical reasons for the creep of the FRTP material, slip or lineation of the PP polymer's molecular chains are assumed.

\section{Conclusions}

The determined specific sensor values of FRTPintegrated CFYS demonstrate that the strength of the force-fit linking between $\mathrm{CF}$ and the reinforcement structure is particularly crucial for sensitivity and linearity of sensors integrated by textiletechnological manufacturing processes. A strong adhesion caused by structural embedding (crimp) can decrease linearity, hysteresis and the gauge factor $k$ simultaneously. According to the requirements on the measuring task, or rather the structural-health monitoring, such as accuracy, repeatability and sufficient signal amplitude at given mechanical exposures, an adequate structural linking or interlacing and for this reason a suitable textiletechnological integration technique has to be chosen for adjustment and warranty of an appropriate signal response characteristic of the CFYS.

It can be assumed, however, that non-linearity and hysteresis of such FRTP-integrated CFYS can be further reduced by selecting low-viscosity and thus more fiber-infiltrating thermoplastic matrices, e.g. polybutylene terephthalate $\eta=(55 \ldots 150) \mathrm{Pa} \cdot \mathrm{s}$; polyamide PA $12 \eta=(80 \ldots 300) \mathrm{Pa} \cdot \mathrm{s}$ (compare polypropylene PP with $\eta=(1000 \ldots 1800) \mathrm{Pa} \cdot \mathrm{s}[16$, 17]), and by using matrix-optimized ("tailored") fiber-sizings or rather filament functionalization for an improvement of the fiber/matrix adhesion.

\section{Acknowledgement}

This article presents a part of the results from the research program DFG CH 174/17-1 and 17-2 at the ITM of Technische Universität Dresden, Germany. The authors would like to thank the German Research Foundation (DFG) for the financial support of the mentioned projects.

\section{References}

[1] Chr. Mersmann, Industrialisierende Machine-VisionIntegration im Faserverbundleichtbau, 2012, Aachen, Apprimus Verlag, ISBN 978-3-86359-062-8, pp. 59 ff

[2] M. Abounaim, C. Cherif, Textile Research Journal, 82(2012)3, 288-298

[3] M. Abounaim, G. Hoffmann, O. Diestel, Ch. Cherif, High performance thermoplastic composite from flat knitted multi-layer textile preform using hybrid yarn, Compos Sci Technol 2011, 71(4):511-9

[4] Ch. Cherif, S. Krzywinski, O. Diestel,Ch. Schulz, H. Lin, P. Klug, Development of a process chain for the realization of multilayer weft knitted fabrics showing complex 2D/3D geometries for composite application. Text Res J 2011. http:// dx.doi.org/10.1177/0040511429602.

[5] K. Schulte, C. Baron, Load and failure analyses of CFRP Laminates by means of electrical resistivity measurements, Compos Sci Technol 1989;36(1):6376

[6] N. Muto, H. Yanagida, T. Naktsuji, M. Sugita, Y. Ohtsuka, Preventing fatal fractures in carbon-fiberglass-fiber reinforced plastic composites by monitoring change in electrical resistivity. J Am Ceram Soc 1993;76(4):875-9

[7] S.K. Wang, D. Wang, D.D.L. Chung, Method of sensing impact damage in carbon fiber polymermatrix composite by electrical measurement, J Mater Sci 2006;41(8):2281-9

[8] N. Muto, Y. Arai, S.G. Shin, H. Matsubara, H. Yanagida, T. Naktsuji, Hybrid composites with selfdiagnosing function for preventing fatal fracture, Compos Sci Technol 2001;61:875-83.

[9] J.W. Cho, J.S. Choi, Relationship between electrical resistivity and strain of carbon fibers upon loading. J. Appl Polym Sci 2000;77(9):2082-7

[10] C. N. Owston, Journal of Physics, 1970, 11, 16151626

[11] M. M. B.Hasan, A. Matthes, P. Schneider, Ch. Cherif, Application of carbon filament (CF) for structural health monitoring of textile reinforced thermoplastic materials, Technology 26(2011)3, DOI: 10.1179/175355511X13007211258881, pp. 128-134

[12] A. Kunadt, E. Starke, G. Pfeiffer, Messtechnische Eigenschaften von Dehnungssensoren aus 
Kohlenstoff-Filamentgarn in einem Verbundwerkstoff. tm - Technisches Messen 77 (2010) 2, S.113-120

[13] A. Horoschenkoff, T. Mueller, A. Kroel, On the characterization of the piezoresistivity of embedded carbon fibers. Proceedings. 17th International Conference on Composite Materials ICCM-17, Edinburgh (Scotland), (27.07.-31-07.2009)

[14] Ch. Cherif, Textile Werkstoffe für den Leichtbau. Berlin, Heidelberg: Springer-Verlag, 2011, ISBN 9783-642-17991-4. pp. 128-130, 141-143

[15] B. D. Choi Entwicklung von ComminglingHybridgarnen für langfaserverstärkte thermo- plastische Verbundwerkstoffe, Dresdner Forschungen - Maschinenwesen 19(2005), S.1-146, Dresden

[16] H.-P Zepf, Faserverbundwerkstoffe mit thermoplastischer Matrix Hochleistungswerkstoffe für rationelle Verarbeitung, Reinningen-Malmsheim: expert-Verlag, 1997, ISBN 3-8169-1390-3, p. 99

[17] M. Neitzel, P. Mitschang, Handbuch Verbundwerkstoffe Werkstoffe, Verarbeitung, Anwendung. München, Wien, Carl Hanser Verlag, 2004, ISBN 3-446-22041-0, p. 116

\section{Appendix A - Tables}

Tab. 1: Overview yarn materials

\begin{tabular}{lcccl}
\hline description & $\begin{array}{c}\text { number of } \\
\text { filaments }\end{array}$ & $\begin{array}{c}\text { yarn count } \\
T t \text { in tex }\end{array}$ & $\begin{array}{c}\text { specific resistance } \rho \\
\text { in } 10^{3} \Omega \cdot \mathrm{cm}\end{array}$ & material \\
\hline Torayca $^{\circledR}$ T300B-1000-50B & 1,000 or 1k & 66 & 1.7 & CF (exPan) \\
Tenax ${ }^{\circledR}$ HTA40-F15 & $1 \mathrm{k}$ & 67 & 1.6 & $\mathrm{CF}(\operatorname{exPAN})$ \\
ITM HG 1 & - & 1,200 & - & GF/PP \\
\hline
\end{tabular}

Tab. 2: Test sequence parameters during cyclical tensile stresses for determining characteristic values of CFYS

\begin{tabular}{|c|c|c|c|c|}
\hline phase & $\begin{array}{l}\text { load } \\
\text { cycles }\end{array}$ & $\begin{array}{l}\text { elongation } \varepsilon \text { in } \% \text { (strain } \\
\text { controlled over } t_{H} \text { ) }\end{array}$ & $\begin{array}{l}\text { exposure } \\
\text { time } t_{H} \text { in } \mathrm{s}\end{array}$ & global testing parameters \\
\hline I & 1 & $0.05 \ldots 0.40 \ldots 0.05$ & 10 & \multirow{2}{*}{$\begin{array}{l}v=5.0 \mathrm{~mm} / \mathrm{min} \text { (strain rate) } \\
F=1.0 \mathrm{~N} \text { (pre-load tensile force) }\end{array}$} \\
\hline II & 5 & $0.05 \ldots 0.20 \ldots 0.40 \ldots 0.20 \ldots 0.05$ & 10 each & \\
\hline
\end{tabular}

Tab. 3: Specific sensor values of bare and un-laminated CFY acting as strain gauge under cyclic tensile loads

\begin{tabular}{lccccc}
\hline \multicolumn{1}{c}{ CFY (3 samples each) } & $\begin{array}{c}\text { gauge } \\
\text { factor } k\end{array}$ & $A_{\text {Lin }}$ in \% & $A_{H y s}$ in $\%$ & $\begin{array}{c}\text { YounG's modulus } \\
E_{I I} \text { in GPa }\end{array}$ & $\begin{array}{c}\text { tensile strength } \\
R_{M, I I} \text { in } \mathrm{MPa}\end{array}$ \\
\hline Tenax $^{\circledR}$ HTA40-F15 & $1.72 \pm 0.2$ & $4.44 \pm 0.9$ & $1.41 \pm 0.8$ & 238 & 3,950 \\
Torayca ${ }^{\circledR}$ T300B-1000-50B & $1.54 \pm 0.2$ & $10.25 \pm 3.0$ & $7.04 \pm 2.3$ & 230 & 3,530 \\
\hline
\end{tabular}

Tab. 4: Characteristic values of woven CFYS in MLW

\begin{tabular}{cccccccc}
\hline $\begin{array}{c}\text { specimen } \\
\text { (Fig. 1) }\end{array}$ & $\begin{array}{c}\text { resistivity } \\
R \text { in } \Omega\end{array}$ & $\begin{array}{c}\text { undula- } \\
\text { tion in } \%\end{array}$ & $\begin{array}{c}\text { gauge } \\
\text { factor } k\end{array}$ & $\begin{array}{c}\text { non-linearity } \\
A_{\text {Lin }} \text { in } \%\end{array}$ & $\begin{array}{c}\text { hysteresis } \\
A_{H_{\text {Hs_CFY }} \text { in } \%}\end{array}$ & $\begin{array}{c}\text { hysteresis } \\
A_{\text {Hys_FRTP }} \text { in } \%\end{array}$ & $\begin{array}{c}\text { tensile stress } \sigma \\
\text { in MPa }\end{array}$ \\
\hline B0.1 & $115.6 \pm 1.4$ & 0.0 & $1.88 \pm 0.3$ & $3.64 \pm 2.0$ & $2.08 \pm 1.4$ & $0.99 \pm 0.8$ & $65 \pm 8.6$ \\
B0.2 & $122.7 \pm 2.8$ & 6.2 & $1.34 \pm 0.2$ & $4.51 \pm 2.0$ & $3.11 \pm 1.9$ & $2.10 \pm 1.3$ & $71 \pm 7.4$ \\
B0.3 & $129.3 \pm 4.0$ & 11.9 & $0.89 \pm 0.2$ & $5.05 \pm 2.2$ & $7.14 \pm 4.2$ & $0.79 \pm 0.6$ & $66 \pm 7.8$ \\
B0.4 & $181.4 \pm 4.3$ & 56.9 & $1.01 \pm 0.2$ & $6.39 \pm 2.6$ & $1.78 \pm 1.7$ & $2.06 \pm 1.3$ & $67 \pm 7.6$ \\
\hline
\end{tabular}

\section{Appendix B - Figures}

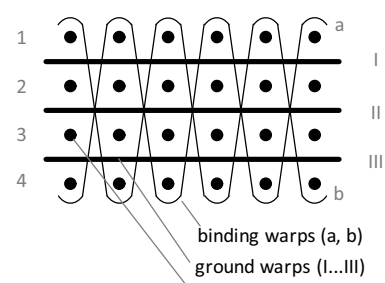

B0.1

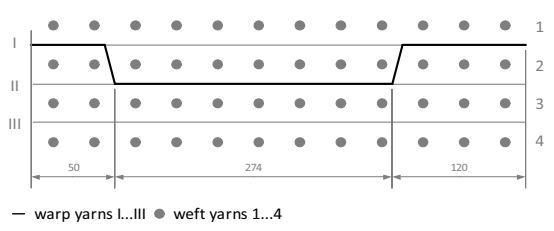

B0.2

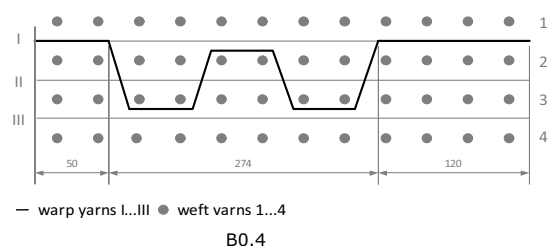


B0.3

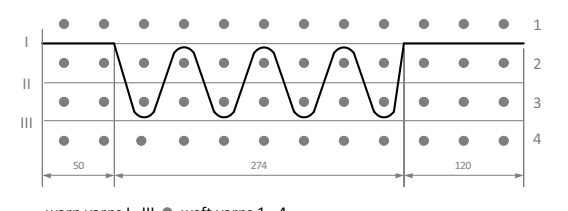

B0.5

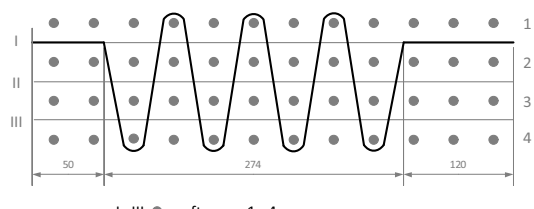

- warp yarns I...III - weft yarns $1 \ldots 4$

Fig. 1: (a) Sectional view in weft direction of a multi-layer weave and (b) variations of interlacing and therefore crimp (B0.1 ...B0.4) with gradually increasing undulation of the CFY acting as strain sensor for in situ monitoring of FRTP

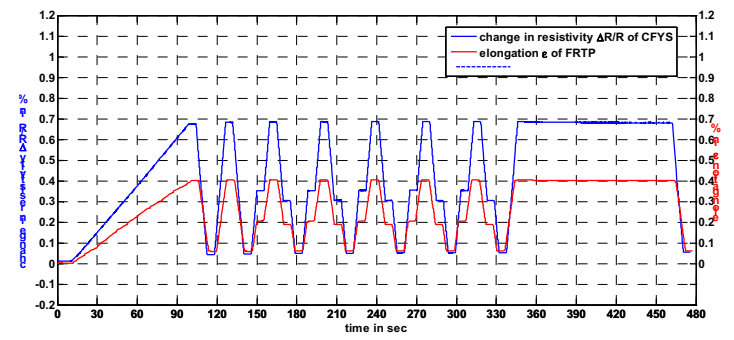

Fig. 2: Sensor characteristic (blue curve) of woven B0.1 CFYS series under cyclical tensile loads

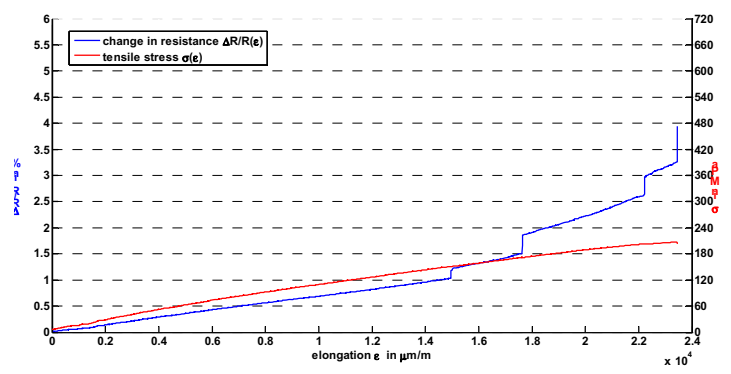

Fig. 3: Sensor behavior (blue curve), exemplary for an CFYS under tensile stress test until full structural damage of the FRTP structure (red curve)

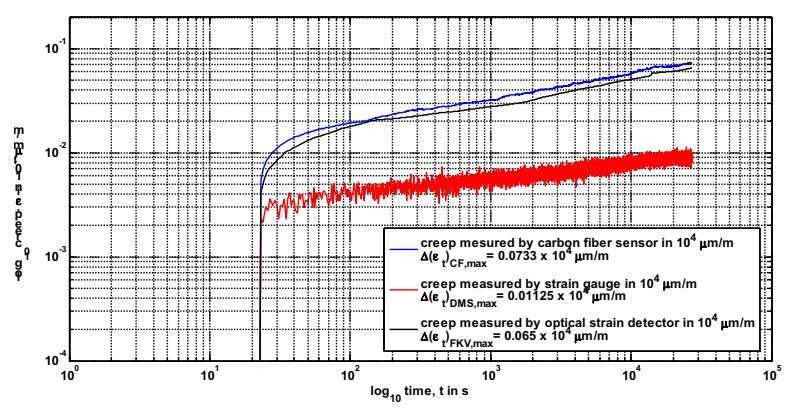

Fig. 4: Effective / indicated creep behavior in tension according to DIN EN ISO 899-1 for a FRTP structure (black curve) measured by an integrated CFYS (blue curve) and conventional strain gauge (red curve) respectively 